\title{
Expeetativa e satisfação dos usuários sobre os serviços oferecidos pelas equipes do Programa Saúde da Familia
}

\author{
| Expectation and satisfaetion about the services offered by the teams of Family Health Program
}

\section{Resumo}

O Programa Saúde da Família (PSF) foi criado em 1994 como uma estratégia para a efetivação do Sistema Único de Saúde (SUS). A consolidação do PSF depende de vários fatores, dentre os quais se destaca o planejamento das ações baseado nas expectativas da população, pois o que pode ser importante e essencial para a equipe de saúde pode não ser para os usuários. É fundamental analisar a satisfação da comunidade com relação às ações executadas a fim de adequá-las às necessidades das pessoas assistidas, pois somente haverá adesão das pessoas, se suas propostas e ações forem condizentes com a necessidade e com a realidade da maioria. Este estudo teve a finalidade de analisar as expectativas e a satisfação dos usuários sobre os serviços oferecidos pelas equipes do PSF de um município do sul de Goiás, para que fossem definidas estratégias de ação condizentes com a realidade da comunidade assistida, visando à consolidação do PSF no município. Foram aplicados questionários estruturados a 1\% das famílias cadastradas (200 famílias) sorteadas aleatoriamente do cadastro de famílias. Os dados foram coletados nos domicílios e a visita acompanhada pelo Agente Comunitário de Saúde (ACS) responsável pela família. Os dados foram tabulados por meio do software EPI INFO 2000 versão 3.02, de domínio público. Concluiu-se que a maioria dos usuários estava satisfeita com os serviços oferecidos pelas equipes do PSF e tinha uma boa expectativa quanto à implantação de novas equipes, contudo o PSF ainda continua sendo um grande desafio a ser enfrentado, desmistificando conceitos e valores reforçados na cultura local pelo modelo assistencial centrado na doença.

\section{Abstract}

The Family Health Program (PSF) was created in 1994 as a strategy for ensuring the Health System (SUS). The consolidation of the PSF depends on several factors, among which stands out the action planning based on the expectations of the population, since what may be important and essential to the health team may not be for users. It is essential to analyze the satisfaction of the community with respect to actions taken in order to adapt them to the needs of people assisted, as there will only be joining people, if their proposals and actions are consistent with the need and the reality of the majority. This study was done in order to analyze the expectations and user satisfaction about the services offered by the teams of PSF from a city of southern Goiás, to be defined strategies for action consistent with the reality of the community attended, in order to consolidate the PSF in. Structured questionnaires were applied to $1 \%$ of the registered families (200 families) randomly selected from the register of families. Data were collected during home visits and accompanied by Community Health Agent (ACS) responsible for the family. Data were tabulated by EPI INFO 2000 software version 3.02, public domain. We conclude that the majority of users were satisfied with the services offered by the PSF teams and had a good expectation of implementation of new teams, yet the PSF remains a challenge to be faced, demystifying concepts and values reinforced in culture site by healthcare model focuses on disease.

\author{
Evonete Maria de Oliveira Marra ${ }^{1}$ \\ Juliana Pereira da Silva Faquim ${ }^{2}$ \\ Julymary Castanheira Carvalho ${ }^{3}$ \\ Soraia Martins Nagao ${ }^{4}$
}

Deseritores: Satisfação do Paciente, Avaliação em Saíde, Programa Saúde da Familia

Keywords: Patient Satisfaction, Health Evaluation, Family Health Program

1 Professora da Eseola Téenica de Saúde da Universidade Federal de Uberlândia, doutoranda em Saúde Pública da Faculdade de Saúde Públitga/USP

${ }^{2}$ Professora Doutora da Faculdade de Odontologia da Universidade Federal de Uberlândia

${ }^{3}$ Especialista em Saúde Coletiva

${ }^{4}$ Especialista em Saúde Coletiva

Para correspondência:

Juliana Faquim

Email:jufaquim@usp.br 
Introdução

As duas últimas décadas foram marcadas por intensas transformações no sistema de saúde brasileiro, intimamente relacionadas com as mudanças ocorridas no âmbito político-institucional.

A VIII Conferência Nacional de Saúde, realizada em março de 1986 é considerada um marco na história da Política de Saúde Brasileira, e consagra os princípios da descentralização, universalização e unificação, preconizados pela Reforma Sanitária, na década de 70. Em 1990 é promulgada a Lei Orgânica da Saúde - Lei $n^{\circ}$ 8080, de 19 de Setembro de 1990, que dispõe sobre as condições para promoção, proteção e recuperação da saúde, organização e funcionamento, e estabelece os princípios e diretrizes que devem reger os serviços como, o acesso universal e igualitário às ações de saúde, com vistas à regionalização e hierarquização, descentralização com direção única em cada esfera de governo, participação da comunidade e atendimento integral, com prioridade para as atividades preventivas, sem prejuízo dos serviços assistenciais. Em 28 de dezembro de 1990 é decretada a Lei $n^{\circ} 8142$ que amparou a participação da comunidade na elaboração de políticas de saúde, participando da fiscalização, do planejamento e do controle e avaliação, por meio das Conferências e Conselhos de Saúde.

Como estratégia para a efetivação do SUS foi criado o Programa Saúde da Família (PSF) visando superar o modelo assistencial tradicional, responsável pela "ineficiência do setor, insatisfação da população, desqualificação profissional e iniquidades"1. Caracterizou-se como uma estratégia de reorientação do modelo assistencial, operacionalizada mediante a implantação de equipes multiprofissionais, que prestam assistência em unidades básicas de saúde e nos domicílios, sendo responsáveis pelo acompanhamento de um número definido de famílias, que passaram a ser o objeto de atenção.

O programa representa ações combinadas à partir da noção ampliada de saúde, que engloba tudo aquilo que possa levar a pessoa a ser mais feliz e produtiva e se propõe a humanizar as práticas de saúde, buscando a satisfação do usuário pelo estreito relacionamento dos profissionais com a comunidade, estimulando-a ao reconhecimento da saúde como um direito de cidadania em busca da qualidade de vida ${ }^{1}$. Os usuários podem participar avaliando e intervindo no planejamento das ações de saúde, exercendo o direito do controle social dentro do SUS2.

Uma das características importantes das diretrizes do SUS diz respeito à participação da comunidade. A participação e o controle social é a expressão mais viva da participação da sociedade nas decisões tomadas pelo Estado no interesse geral, e suas manifestações mais importantes são o cidadão e o usuário no centro do processo de avaliação $^{3}$. O controle social fortalecido com o advento do SUS e o incentivo a participação da comunidade pressupõem uma concepção do usuário com competência para avaliar e intervir modificando o próprio sistema ${ }^{2}$.

Sendo a população em sua totalidade beneficiada com projetos e ações em saúde, a opinião dos usuários quanto à qualidade da atenção é considerada de extrema relevância quando se busca avaliar esses serviços. Importante também é saber como a população adscrita às equipes da Estratégia de Saúde da Família (ESF) avalia o atendimento oferecido, de modo a repensar as práticas profissionais ou intervir sobre a forma de organização dos serviços, visando seu aprimoramento ${ }^{4}$.

A participação livre e a crítica dos usuários podem contribuir para o empoderamento deste grupo populacional, questões estas essenciais para a viabilização de políticas de promoção da saúde e prevenção de agravos e controle de enfermidades ${ }^{5}$. Desse modo, a melhoria dos programas de saúde pode ser baseada no processo de avaliação apoiado na análise do sistema por meio da ótica do usuário, servindo de parâmetro para as ações e políticas de saúde.

Avaliar é uma oportunidade dos diferentes atores, como os provedores de serviços em saúde, a população, os prestadores de serviços, os profissionais de saúde, os políticos, as universidades $\mathrm{e}$ as demais instituições de aprendizagem, participar da construção e aperfeiçoamento do SUS, sendo ao mesmo tempo um processo de aprendizagem e de controle social ${ }^{6}$.

"[...] A avaliação é, pois, um poderoso instrumento de mudança que não deve ser visto como uma ameaça, mas sim como um incentivo, para que diferentes serviços de saúde cumpram padrões minimos de qualidade [...]"7.

"[...] A avaliação de programas e
serviços de saúde é de fundamental
importância no processo de
amadurecimento do SUS. Instituí-la 
enquanto prática sanitária é um desafio posto para gestores, profissionais de saúde e todos os atores sociais que acreditam que as reformas do sistema de saúde se fazem a partir da reflexão sobre os processos concretos de recriação do cotidiano dos serviços de saúde [...]"8

No contexto de programas e serviços de saúde, a avaliação é um processo técnicoadministrativo destinado à tomada de decisão que evolve momentos de medir, comparar e emitir juízo de valor. As diretrizes estimuladas na implementação da avaliação em programas de saúde têm-se diversificado ao longo dos anos e entre as mais difundidas, destacam-se as implementadas pela Organización Panamericana de la Salud Y Organización Mundial de la Salud (OPAS/OMS) na década de 1980: desenvolvimento de avaliações globais, visando apoiar a expansão da rede de serviços de saúde no continente latino-americano; desenvolvimento de avaliações visando a intervenções gerenciais específicas e avaliações que visam melhorar as condições de eficiência realizadas mediante a comparação das características existentes nos programas e serviços com padrões de referência.

Ao realizar uma avaliação em programas de saúde, deve-se ter em mente que esses programas têm uma população-alvo ou usuários que são parte do processo de organização e prestação das atividades, além disso, o produto final de atividades dos serviços de saúde não é um objeto material resultante da transformação dos insumos utilizados no processo da atenção, por isso é recomendável que a avaliação seja sempre definida tendo como foco principal o resultado que se espera alcançar no usuário, ou seja, o que foi incorporado pelos usuários na ocasião de sua passagem e interação nesse processo de trabalho ${ }^{8}$.

A consolidação do Programa Saúde da Família depende de vários fatores, dentre os quais se destaca o planejamento das ações baseado nas expectativas da população, pois o que pode ser importante e essencial para a equipe de saúde pode não ser para os usuários. É fundamental analisar a satisfação da comunidade com relação às ações executadas a fim de adequá-las às necessidades das pessoas assistidas, pois somente haverá adesão das pessoas, se suas propostas e ações forem condizentes com a necessidade e com a realidade da maioria.

Neste sentido, o objetivo do presente estudo foi analisar a expectativa e a satisfação dos usuários referente aos serviços oferecidos pelas equipes da ESF em município do sul de Goiás, para que estas possam adequar suas estratégias de ação garantindo melhores condições de saúde para a população, assim como a consolidação do Programa Saúde da Família.

\section{Materiais e Método}

Trata-se de um estudo de corte transversal, de abordagem quantitativa realizado nas áreas adscritas do PSF de um município do sul de Goiás, onde residem 19.595 famílias, assistidas por quatorze equipes, que correspondem a aproximadamente $80 \%$ da população da cidade. Foi utilizado o cadastro de famílias e sorteado aleatoriamente $1 \%$ das famílias cadastradas, de cada área de saúde, garantindo-se desta forma, a representatividade equitativa entre as mesmas. A amostra final foi constituída por 200 famílias.

Os dados foram coletados nos domicílios dos usuários, durante os meses de abril, maio e junho de 2008. Os participantes deste estudo não foram identificados, foram orientados sobre os objetivos e procedimentos da pesquisa e assinaram o Termo de Consentimento Livre e Esclarecido. As visitas domiciliares para aplicação dos questionários foram acompanhadas pelos Agentes Comunitários de Saúde responsáveis por cada família.

O estudo foi realizado seguindo as normas que regulamentam a pesquisa em seres humanos, contidas na Resolução n 196/96 do Conselho Nacional de Saúde. O projeto de pesquisa e seus anexos foram submetidos à análise e aprovação pelo Comitê de Ética e Pesquisa da Universidade Federal de Uberlândia, tendo recebido parecer favorável sob o registro CEP/UFU:329/07.

Realizou-se um pré-teste por meio da aplicação de um questionário composto por perguntas abertas, a 10 usuários, com a finalidade de subtrair as alternativas para compor o questionário definitivo.

Em seguida, realizou-se um estudo piloto no qual se aplicou o questionário estruturado a 20 sujeitos do PSF do próprio município, com o objetivo de evitar e corrigir possíveis falhas na formulação das questões e respectivas alternativas. Os dados obtidos foram tabulados por meio do software EPI INFO 2000 versão 3.0210, de domínio público. 


\section{Resultados e Diseussão}

A distribuição das faixas etárias está representada na Tabela 1.

\begin{tabular}{l|l}
\hline Faixa etária & $\%$ \\
\hline$<18$ anos & 2,0 \\
$18-20$ anos & 2,0 \\
$21-30$ anos & 20,5 \\
$31-40$ anos & 18,5 \\
$41-50$ anos & 21,0 \\
$51-60$ anos & 16,0 \\
Acima de 61 anos & 20,0 \\
\hline
\end{tabular}

Tabela 1. Faixas etárias dos indivíduos entrevistados.

Os dados relativos às características sóciodemográficas permitiram observar que todos os entrevistados residiam na zona urbana, em casas de alvenaria sendo que $71,5 \%$ das famílias residiam em casa própria; $86,0 \%$ das residências tinham água encanada (tratada), 64,5\% dos domicílios eram servidos com rede de esgotos e $100 \%$ contavam com serviço público de coleta de lixo. Com relação à renda mensal da família, 33,0\% responderam receber um salário mínimo, 23,5\% recebiam dois salários e 17,0\% recebiam três. $\mathrm{O}$ meio de comunicação mais utilizado e considerado de maior importância para a maioria dos entrevistados foi a televisão $(60,8 \%)$, seguido de rádio $(34,7 \%)$. Somente $4,5 \%$ dos participantes da pesquisa relataram acesso à internet.

Os participantes da pesquisa eram predominantemente do gênero feminino $(86,5 \%)$ e a maioria $(67,7 \%)$ tinha cursado apenas o ensino fundamental (incompleto - 5,5\%; completo - 12,2\%). O grau de escolaridade referente ao ensino médio foi citado em 30,5\% das respostas (incompleto - 12,8\%; completo - 17,7\%). Apenas 2,4\% dos entrevistados relataram superior incompleto ou completo $(2,4 \%)$. A predominância do gênero feminino nas entrevistas pode se dever ao fato destas terem sido realizadas no domicílio dos usuários e no período diurno, quando as mulheres estão em casa, ocupadas com os afazeres domésticos ${ }^{11}$. A frequência do analfabetismo funcional foi uma questão que chamou a atenção, devido ao fato de ser um importante indicador na sociedade moderna, que cada vez mais exige maior grau de escolaridade ${ }^{5}$.

Observou-se que 70,0\% dos entrevistados estavam empregados quando foi aplicado o questionário e as respostas mais frequentes com relação à profissão foram “do lar" (40,5\%) seguido por "aposentadas" (14,0\%). A predominância destas mesmas profissões foi observada também por Cotta $^{5}$ em um estudo realizado em Teixeiras - MG. Quando se perguntou aos entrevistados o que esperavam com relação à saúde após a implantação do PSF no município, 59,5\% responderam que a saúde de sua família e da comunidade iria melhorar. Isto demonstra que a maioria da população tinha, na ocasião, uma boa expectativa com relação aos serviços oferecidos. Apenas 5,5\% acreditavam que não haveria nenhuma mudança no cenário da saúde em Itumbiara.

Este resultado corrobora o estudo realizado por Teixeira ${ }^{12}$ em Vitória da Conquista BA, onde $81,4 \%$ dos usuários relataram melhora na saúde das famílias após a implantação do PSF. No estudo de Aguiar e Moura ${ }^{13}$ verificou-se que 93,3\% dos entrevistados do distrito de Bom Princípio $\mathrm{CE}$ reportaram ter havido mudanças positivas quanto a assistência à saúde a partir da implantação do PSF. O reconhecimento de melhora dos serviços pela população foi identificado também por $\operatorname{Cotta}^{5}$ no município de Teixeiras - MG.

Quando foi perguntado se o que esperavam ocorreu após a implantação do PSF e se os problemas de doença da comunidade iriam diminuir com o trabalho das equipes, 92,0\% responderam que sim, o que confirma a credibilidade da população na nova proposta de atenção à saúde das pessoas.

A maioria dos participantes do estudo $(82,0 \%)$ respondeu que os serviços de saúde oferecidos pelas equipes do PSF são um direito de todos e dever do Estado. Observou-se, portanto, que os usuários dos serviços de saúde tinham consciência do direito que lhes assiste, apesar do pouco acesso à educação nos níveis médio e superior. A população, conhecedora de seus direitos e também de seus deveres e responsabilidades, pode contribuir efetivamente para a melhoria das ações de saúde, por meio da sua representação legal nos Conselhos e Conferências de Saúde Municipais.

Conforme disposto na Constituição Federal de 1988, no Artigo 196, “a saúde é direito de todos e dever do Estado, garantido mediante políticas sociais e econômicas que visem à redução do risco de doença e de outros agravos e ao acesso universal e igualitário às ações e serviços para sua promoção, proteção e recuperação" 14 .

$\operatorname{Trad}^{2}$ argumentaram que quanto maior for 
o nível de informação do usuário sobre os objetivos, atividades e regras de funcionamento do PSF, maior será o grau de satisfação com relação ao programa. O nível de informação foi condicionado ao grau de escolaridade e à eficácia das estratégias de comunicação e informação em saúde.

Ressalta-se que $10,5 \%$ e $6,5 \%$ dos entrevistados acreditava que o PSF seria um programa voltado para o atendimento de pessoas de baixa renda ou seria oferecido como um favor, respectivamente, o que contraria a Lei 8080/1990 e, por conseguinte, os princípios e diretrizes da estratégia saúde da família.

Quando as 200 pessoas foram perguntadas sobre o que consideravam mais importante na organização dos serviços do PSF, 71 disseram que são profissionais competentes, 50 que foi a rapidez na marcação de consultas com especialistas e 32 que foi a maior disponibilidade de remédios e apenas 6 disseram ser atividades preventivas e educativas.

Por meio deste resultado, principalmente com relação à valorização da especialização, observou-se que os usuários ainda conservam conceitos ultrapassados de atenção à saúde. Ora, quando se clama por médicos especialistas, presume-se que ou os usuários ainda não entenderam a proposta da estratégia de saúde da família ou a atenção primária não está sendo resolutiva.

De acordo com documentos oficiais cerca de $80,0 \%$ das necessidades da população deveriam ser resolvidas na atenção primária. À medida que isso não ocorre, sobrecarrega o nível de atenção secundário, reduzindo $\mathrm{o}$ acesso das pessoas $\mathrm{e}$ elevando os custos. Os dados refletem também que a maioria das pessoas não tinha consciência de que as atividades de promoção de saúde e prevenção devem ser prioridades no PSF, em oposição ao modelo hospitalocêntrico antigo, baseado em ações curativas.

Quando se perguntou às mesmas pessoas o que consideravam menos importante, 193 apontaram a televisão na recepção.

Constatou-se, nesta pesquisa, que $99,5 \%$ das pessoas já precisaram de algum serviço oferecido pelo PSF sendo que $94,5 \%$ relataram que os profissionais do PSF são atenciosos e 71,5\% que o atendimento foi resolutivo.

Entretanto, $45,0 \%$ das pessoas relataram não participar de atividades coletivas, o que é preocupante, pois significa que grande parte da população ainda não se conscientizou que a prevenção e a participação em atividades educativas são essenciais para a melhoria da saúde.

Segundo Ronzani ${ }^{15}$, as justificativas para a não participação dos entrevistados e seus familiares às atividades são que elas não correspondem às suas necessidades, não há interesse em participar ou os entrevistados ignoram a existência dessas.

Quando os usuários foram perguntados sobre qual foi o serviço mais procurado no PSF, $62,8 \%$ apontaram as consultas, $14,1 \%$ exames e $12,6 \%$ remédios. Quanto mais o profissional limita sua ação na unidade de saúde, restringindo o atendimento no domicílio apenas em casos de doença, mais difícil se torna a reversão do modelo centrado na doença e mais se distancia dos propósitos filosóficos do PSF 12 .

Os usuários relataram que dentre as atividades extra clínicas promovidas pelo PSF estavam as palestras $(82,7 \%)$, as datas comemorativas $(11,8 \%)$ e as caminhadas $(5,5 \%)$. As mais frequentadas pelos usuários participantes foram as palestras $(81,7 \%)$.

Ronzani ${ }^{15}$ relataram a não participação da população estudada em atividades desenvolvidas pela Unidade de Saúde que não estivessem relacionadas à assistência médica. Relataram que apenas $14,4 \%$ da amostra participavam de alguma atividade extra consulta.

O Manual do PSF orienta que é dever social das equipes do PSF promover palestras educativas que levem informações à comunidade, no sentido de ampliar conhecimentos da população em geral sobre as principais doenças. Os profissionais reconhecem a importância das ações educativas que possam revelar à população a necessidade de saber viver uma vida saudável e conhecer a doença e sua prevenção, mas encontram dificuldades para desenvolver um processo educativo, devido à falta de espaço e de materiais educativos e didáticos para a realização das palestras, nas unidades básicas de saúde ${ }^{16}$.

A educação em saúde, principalmente no PSF, deve superar o modelo tradicional, baseado em repasses de informações com tradição autoritária e normatizadora, com imposição de normas e condutas ${ }^{17}$.

"Ao buscar-se uma prática educativa
mais participativa, construindo saberes e
práticas junto aos usuários de saúde, com
fortalecimento de diálogos, de negociação
entre os diversos atores, com
conhecimento dos seus padrões culturais é
possivel reorientar as práticas de saúde,
tornando-as mais integradas à vida local
[...]"17 
O fato dos entrevistados não relatarem a participação em reuniões de planejamento das atividades causa preocupação, uma vez que o controle social é direito da população que deve ser incentivado pelas equipes.

Os usuários reconheceram que houve melhoria na saúde das famílias, fato atribuído principalmente à facilidade no atendimento $(27,8 \%)$, à proximidade do PSF com o domicílio $(26,2 \%)$ e ao incentivo do Agente Comunitário de Saúde (ACS) para que procurassem o PSF $(18,5 \%)$.

O nível de satisfação do usuário reflete a qualidade nos diversos momentos do atendimento. Assim, o modo como os cuidados técnicos são dispensados ou recebidos, no relacionamento cliente/serviço de saúde, é um importante índice para avaliar a qualidade da assistência. Portanto, a boa relação entre os profissionais e o paciente é a maior contribuição que se pode oferecer ao paciente, com efeitos positivos no tratamento ${ }^{18}$.

Araújo ${ }^{19}$ notificaram que muitos usuários do PSF de duas comunidades de João Pessoa - PA estão insatisfeitos com $\mathrm{o}$ modelo de organização hierarquizado dos serviços de saúde. Sentem sua liberdade de procurar os serviços de sua preferência cerceada, uma vez que devem, primeiramente, buscar o primeiro atendimento na ESF, antes de procurarem o hospital. No entanto, a grande maioria está satisfeita com a assistência, principalmente devido às visitas domiciliares realizadas pelo ACS e a localização da Unidade de Saúde da Família perto de casa. As principais mudanças observadas pelos moradores dizem respeito à acessibilidade e à humanização na assistência, decorrentes do novo modo de agir dos profissionais, com vistas ao acolhimento e ao vínculo estabelecidos com as famílias.

$O$ que se almeja, no PSF, entre outros objetivos é facilitar o acesso da população aos serviços.

"[...] O acesso como a possibilidade da consecução do cuidado de acordo com as necessidades tem inter-relação com a resolubilidade e extrapola a dimensão geográfica, abrangendo aspectos de ordem econômica, cultural e funcional de oferta de serviços [...]". "Ressalta-se, portanto, a importância da qualificação do acesso, incluindo aspectos da organização $e$ da dinâmica do processo de trabalho, considerando a contribuição e a importância de análises de vários aspectos (geográficos e socioeconômicos, entre outros). No contexto atual de construção do SUS, é fundamental que sejam potencializados caminhos trilhados e experimentados, a exemplo da proposta de acolhimento, como diretriz operacional dos serviços de saúde [...]". "[...] Por fim, acesso $e$ acolhimento constituem-se como desafios na construção do cuidado integral e como elementos de fundamental importância para a gestão e avaliação de serviços de saúde" 20

As pessoas que acharam que o trabalho das equipes do PSF não tem contribuído para a melhoria da saúde das famílias justificaram que foi devido à dificuldade para conseguir consultas com especialistas $(64,7 \%)$ e à dificuldade para a realização de exames $(35,2 \%)$. Estes resultados estão em concordância com os de $\mathrm{Trad}^{2}$ ao verificarem que, na maioria das áreas de abrangência investigadas, persistia uma dificuldade na marcação de consultas com especialistas e exames de laboratório, ficando claro a precariedade do processo de referenciamento e a baixa cobertura no nível primário. Neves ${ }^{21}$ entendem que o serviço de referência e contra referência devem ser estruturados para facilitar o acesso e o retorno do usuário para a atenção primária, o que daria maior credibilidade ao programa e, consequentemente, maior satisfação. Nas circunstâncias desta pesquisa pode-se sugerir que o trabalho do PSF não está sendo resolutivo, uma vez que grande parte das pessoas relatou necessidade de consultas especializadas e exames complementares. Pode-se inferir também que o trabalho da equipe não tem sido efetivo em mudar o conceito de atenção à saúde, que continua centrado na medicalização. Os usuários continuam percebendo o atendimento individual e curativo e a prescrição de medicamentos como a alternativa concreta de atendimento às suas necessidades de saúde e não compreendem as outras atividades tais como o trabalho educativo e as ações coletivas, como propostas desenvolvidas para melhorar as condições de sua saúde ${ }^{22}$.

Quando se perguntou aos entrevistados se o ACS visita os domicílios, 98,0\% responderam que sim e que a visita do ACS não incomodava. O ACS é responsável pelo acompanhamento de aproximadamente 150 famílias que vivem em seu território de atuação, sendo imperativa sua total 
identificação com o mesmo. "Ele precisa estar atento a vários verbos importantes no seu trabalho: identificar, encaminhar, orientar, agir, defender, estimular, convencer, mobilizar, refletir, ajudar, reagir, recusar, cuidar, notificar, convocar, convidar, reunir, e tantos outros. Afinal, a vida se constrói com ações e para vivê-la é preciso que estas aconteçam" ${ }^{23}$.

"O ACS é um agente de mudanças, quando procura aprender com as experiências das pessoas, com os profissionais de saúde, compartilhando o que foi aprendido com a própria comunidade. Agindo assim, ele estará crescendo junto com as pessoas da sua comunidade no entender, no saber, no fazer, não somente na área da saúde, mas também no despertar do potencial humano e da consciência coletiva" 23 .

O ACS é um elo entre a comunidade e os serviços de saúde e o fato de residir na área de abrangência confere-lhe uma atuação singular ${ }^{24}$. Ele é identificado pelos usuários como o mediador entre o domicílio e a Unidade de Saúde da Família 25 tornando menos árduo o processo de acesso ao cuidado ${ }^{2}$. Cotta ${ }^{5}$ observaram que $42,3 \%$ dos usuários se mostraram muito satisfeitos e $55,5 \%$, satisfeitos com o trabalho do ACS. Segundo Nascimento e Correa ${ }^{24}$ os ACS consideram que seu papel vai além de um elo à medida que dá voz para a comunidade ou expressa a voz da comunidade dentro dos serviços de saúde.

Ao analisar a frequência das visitas domiciliares realizadas pelo ACS, observou-se que a metade dos usuários entrevistados foi visitada uma vez por mês e 38,0\% gostariam de receber a visita quinzenalmente, $37,5 \%$ acharam que uma visita mensal é suficiente e $23,0 \%$ gostariam de ser visitados semanalmente. Cotta ${ }^{5}$ constataram que a visita domiciliar ocorria habitualmente no município de Teixeiras-MG, sendo que $82,5 \%$ dos usuários recebiam visitas uma vez ao mês.

Mandú 25 relataram, por meio de seu conjunto de entrevistas, que as visitas do ACS às famílias permitem o estabelecimento de estreitas relações afetivas que são muito valorizadas. Há que se considerar que o respeito à vida privada e o comportamento ético são apresentados como essenciais à abertura do domicílio às ações profissionais. No entanto, segundo os mesmos autores, a visita frequente e compulsória nem sempre é bem-vinda, apesar de ser referida como importante e necessária, mas não para a própria família. As visitas podem representar uma intromissão do serviço na vida das pessoas ferindo sua privacidade e, quando ocorre desta forma, é recusada.

Segundo Brasil ${ }^{23}$ o ACS deve visitar pelo menos uma vez por mês aproximadamente 500 pessoas, prestando cuidados primários e auxiliando-as a cuidar da própria saúde por meio de ações individuais e coletivas.

A vontade de ser visitados por outros membros da equipe do PSF, além do ACS, foi demonstrada por $45,5 \%$ dos entrevistados. Destes, $59,3 \%$ gostariam de receber a visita do médico, $28,6 \%$ preferiam receber o enfermeiro, $7,7 \%$ optaram pelo dentista e $4,4 \%$ citaram o técnico de enfermagem. De acordo com as recomendações de Ministério da Saúde, a necessidade de visitas aos usuários da área adstrita deve ser identificada pelo ACS, que é o elo entre as famílias e a equipe. A rotina de visitas está relacionada ao planejamento do trabalho no município e depende, entre outras coisas, da coordenação local.

As respostas dos entrevistados quando foi perguntado por quem gostariam de ser visitados, refletiu o valor que o usuário agrega aos profissionais de saúde. $\mathrm{O}$ desejo dos entrevistados em receber o médico e o enfermeiro foi citado por $59,3 \%$ e $28,6 \%$ respectivamente. A profissão médica, nela incluída a enfermagem, de uma forma geral é associada com a preservação da vida e com o alívio da dor, o que pode explicar a preferência pela visita destes dois profissionais.

De acordo com Trad', ao se expressar a satisfação quanto a equipe do PSF, os usuários destacaram preferencialmente o ACS e o médico. $\mathrm{O}$ primeiro por ser um mediador entre a comunidade e os profissionais da saúde e o segundo por ser reconhecidamente de grande status, cuja visita a casas humildes tem um efeito impactante. A preferência dada ao médico e ao enfermeiro, segundo Mandú 25 justifica-se pelo fato de serem considerados "mais preparados" para realizarem as visitas identificadas como necessárias, além da importância social atribuída a ambos, em particular ao médico.

$O$ fato de somente $7,7 \%$ das pessoas citarem o cirurgião-dentista (CD) também demonstra que há necessidade de maior integração deste com a equipe e com a população. $\mathrm{O}$ trabalho do $\mathrm{CD}$ é, geralmente, voltado para o atendimento de uma demanda carente de necessidades clínicas acumuladas, dentro do modelo tradicional, o que cerceia sua participação na realização de atividades extra consultório como as visitas aos domicílios. O próprio Ministério da Saúde recomenda a maximização da hora clínica do $C D$, que deve destinar entre $75,0 \%$ a $85,0 \%$ das horas trabalhadas ao atendimento no consultório, enquanto as demais seriam gastas com visitas 
domiciliares, planejamento das atividades e reuniões de equipe ${ }^{26}$. Isto dificulta sua integração no universo do trabalho no PSF, como demonstrado por Carvalho27, que observou que o CD é o membro da equipe do PSF que menos conhece a população assistida. Além disso, sabe-se que a população ainda não está consciente de que os problemas bucais podem comprometer sistemicamente o ser humano, por isso, tanto a saúde bucal quanto os $\mathrm{CD}$ não são valorizados na proporção dos outros profissionais que cuidam da saúde do indivíduo.

Ao serem questionados sobre os motivos das reclamações sobre a atenção nas unidades de saúde, $47,3 \%$ dos respondentes citaram demora no atendimento, 33,3\% que havia necessidade de melhoria no atendimento da recepção e $24,5 \%$ disseram que tinham dificuldade para conseguir remédio. Algumas pessoas (19,3\%) responderam que o médico não era muito bom e era mal educado. A última queixa demonstrou a falta de empatia dos profissionais do PSF com a população atendida que, muitas vezes, necessita mais de atenção do que do tratamento clínico propriamente dito. Neste aspecto, este estudo concorda com o de Aguiar e Moura ${ }^{13}$, afirmando que o relacionamento médico-cliente foi considerado insatisfatório pelos usuários e sugeriu uma reavaliação do desempenho profissional pela Coordenação Municipal do distrito de Bom Princípio$\mathrm{CE}$, cujas queixas deveriam ser minimizadas por meio de capacitação e/ou estratégias voltadas para a motivação e a autoestima profissional.

A falta de perfil de muitos profissionais que atuam na estratégia saúde da família tem sido apontada principalmente pelos gestores dos serviços. Muitos não recebem formação acadêmica adequada ou treinamentos satisfatórios, encontrando-se desqualificados para o trabalho, filosófico, ética ou clinicamente. $\mathrm{O}$ vínculo de muitos profissionais com o serviço, manifestado muitas vezes na forma de contratação por meio de favoritismo, não assegura o real envolvimento com o trabalho, conforme os preceitos do SUS e do PSF.

Os usuários dos serviços devem ser tratados com respeito e consideração, em qualquer circunstância incluindo a boa recepção nas unidades de saúde. A escuta ao usuário deve ser garantida e permitir a avaliação da atuação da equipe de saúde da família, uma vez que pode apontar a necessidade de melhoria e desafios, assim como sugerirem estratégias para a superação das dificuldades existentes ${ }^{13}$.

Sberse e Claus $^{22}$ consideraram em seu trabalho que as respostas dos usuários como a falta de especialista, falta de atendimento 24 horas por dia e nos finais de semanas e feriados, bem como falta de médicos diariamente são entendidos como aspectos dificultadores da utilização da unidade básica de saúde.

As pessoas que participaram da pesquisa classificaram os serviços oferecidos pelo PSF como: bom $(45,5 \%)$, ótimo $(20,5 \%)$ e muito bom $(16,5 \%)$. Resultados semelhantes foram descritos por Aguiar e Moura $^{13}$ ao verificarem que $80 \%$ dos sujeitos da pesquisa classificaram os serviços como excelente ou bom. Segundo estes autores é preciso que a equipe de saúde fique atenta à expectativa das pessoas assistidas pelo SUS, que pode ser baixa ou haver conformismo ou pode estar associada ao medo de reclamar e ser mal atendidas. Ressalta-se ainda o viés que pode ocorrer quando o entrevistador é um membro da equipe do PSF, pelos sentimentos de que pode inspirar, levando a respostas que não revelem verdadeiramente a percepção sobre os serviços.

A dificuldade usual para conseguir atendimento resulta em baixa expectativa. "O simples fato de ser atendido já pode produzir satisfação, pois as pessoas não esperam muito das instituições públicas" 28 . Por outro lado, Rodríguez e López ${ }^{29}$ relataram associação entre o grau de escolaridade e a satisfação com os serviços oferecidos, ou seja, pessoas com menor grau de escolaridade tendem a emitir menos juízo de valor e ser mais transigentes com os serviços de saúde que lhes são prestados. Ao contrário, no presente estudo, a maioria dos entrevistados tinha cursado apenas o ensino fundamental, sendo que 95,5\% classificaram os serviços como bom, muito bom, ótimo e excelente.

Vaitsman e Andrade ${ }^{28}$ por outro lado, consideram que o aspecto da expectativa é um dos mais complexos e nem sempre reflete a realidade, uma vez que pacientes podem ter aprendido a diminuir as suas expectativas quanto aos serviços e uma boa avaliação pode ser fruto de uma baixa capacidade crítica dos usuários.

A pesquisa possibilitou aos usuários a oportunidade de apresentarem sugestões para a melhoria do trabalho no PSF. Dentre as mais citadas destacaram-se a ampliação da equipe médica, sendo que $86,8 \%$ pediram a inclusão de ginecologista e pediatra e $72,3 \%$ o aumento da variedade de medicamentos. Este dado demonstrou e reforçou que a cultura das especialidades na área médica estava incorporada no conceito de medicina efetiva, pela população, sendo incoerente com as diretrizes que norteiam o 
SUS, que orientam a atenção centrada no médico generalista.

As respostas que sugeriram o aumento da variedade de medicamentos juntamente com as citadas anteriormente, remetem para a medicalização como uma questão ultrapassada que a atual estratégia de atenção, a todo custo, tenta superar. As respostas menos frequentes disseram respeito ao aumento da frequência das visitas pelos profissionais. Isto confirma que a população não acreditava na importância das visitas e valorizava mais o ambiente clínico para a resolução de seus problemas. Tal dado pôde revelar, também, a dificuldade de se desenvolver um trabalho voltado para a promoção da saúde e para a prevenção das doenças, já que os fatores associados ao processo saúde-doença, como os determinantes socioeconômicos e culturais, podem ser percebidos mais facilmente no âmbito dos domicílios. Neves ${ }^{21}$ ressaltam que os usuários não entendem ou não estão informados sobre a filosofia do PSF quando se queixam da existência apenas do médico generalista para o atendimento da demanda ou argumentam a ausência de especialistas neste modelo de atenção.

As sugestões apresentadas pelos usuários indicam a necessidade de melhoria do trabalho da equipe de saúde da família. Segundo Aguiar e Moura $^{13}$ deve-se abrir espaço nos serviços de saúde, de maneira sistemática e contínua, para a participação da população das áreas de abrangência, a fim de possibilitar o controle e a avaliação contínua da qualidade das ações.

Quando os entrevistados foram perguntados sobre suas expectativas futuras em relação ao PSF, $39,0 \%$ disseram que haverá implantação de mais equipes, $31,0 \%$ que outros profissionais deverão ser inseridos na equipe e $15,5 \%$ que serão liberadas mais vagas para consultas especializadas. Isto reflete a satisfação e a confiança da população no PSF. Por outro lado, evidencia-se a esperança de profundas mudanças na organização dos serviços, como a inclusão de outros profissionais e de médicos especialistas na equipe.

\section{Conclusões}

De acordo com a metodologia utilizada e os resultados obtidos concluiu-se que:

a) A maior parte dos entrevistados achava que o trabalho das equipes do PSF estava contribuindo para a melhoria da saúde da comunidade; b) As pessoas que usavam os serviços estavam satisfeitas e achavam que os serviços de saúde eram resolutivos;

c) Os entrevistados consideraram que a presença de profissionais competentes no PSF era muito importante e muitos relataram a importância de haver maior disponibilidade de medicamentos e a necessidade de rapidez na marcação de consultas especializadas;

d) A maioria das pessoas achava que a visita do ACS era importante para auxiliar na resolução dos seus problemas de saúde e gostaria de ser visitada entre 15 ou 30 dias por eles;

e) Poucos relataram a necessidade de visitas domiciliares de outros profissionais da equipe;

f) O serviço mais procurado era a consulta e a participação nas atividades coletivas era baixa, sendo que as reuniões para planejamento das atividades não contavam com a participação da população;

g) As pessoas relataram que a facilidade para conseguir o atendimento e a proximidade às suas residências eram as principais vantagens do PSF e que a dificuldade na marcação de exames e consultas especializadas eram os principais problemas enfrentados;

h) As reclamações mais citadas foram demora no atendimento e necessidade de melhoria do atendimento na recepção e as sugestões que eles mais optaram para a melhoria dos serviços foram a ampliação da equipe médica com inclusão de especialistas e o aumento da variedade de remédios.

Concluiu-se que a maioria dos usuários do PSF estava satisfeita e tinha uma boa expectativa quanto à implantação de novas equipes mesmo com todos os problemas que ainda existiam, relatando também a necessidade de inserção de profissionais de outras áreas da saúde na equipe.

O PSF continua sendo um grande desafio a ser enfrentado, no que se refere à implantação das políticas de atenção básica em saúde no Brasil, visto que se caracteriza por um campo da prática ainda pouco experimentado pelos diferentes profissionais que integram as suas equipes.

A conscientização dos usuários e dos 
profissionais das equipes com o novo modelo de assistência à saúde é fundamental. É necessário que os profissionais reaprendam o trabalho a partir de dinâmicas relacionais, somando entre si os conhecimentos para produzir os serviços de saúde utilizando o máximo da sua potência para resolver efetivamente os problemas de saúde dos usuários.

Sendo assim as equipes precisam desmistificar conceitos e valores reforçados na cultura local pelo modelo assistencial centrado na doença e reformular uma nova estratégia de ação que valorize e considere hábitos, crenças e valores culturais da comunidade.

Para a consolidação de tudo que foi proposto o PSF precisa de apoio político, administrativo e financeiro, assim como qualificação e valorização dos recursos humanos, uma vez que todo esse processo de mudança do modelo de assistência à saúde depende não só de ações intersetoriais, como também de vontade e competência dos atores sociais envolvidos.

\section{Referêneias}

1. Brasil. Ministério da Saúde. Secretaria de Assistência à Saúde. Coordenação de Saúde da Comunidade. Saúde da família: uma estratégia de organização dos serviços de saúde. Brasília, 1996.

2. Trad LAB, Bastos, ACS, Santana, EM, Nunes, MO. Estudo etnográfico da satisfação do usuário do Programa de Saúde da Família (PSF) na Bahia. Ciência e Saúde Coletiva 2002; 7(3):581-589.

3. Crevelim, MA. Participação da comunidade na equipe de saúde da família: É possível estabelecer um projeto comum entre trabalhadores e usuários? Ciência e Saúde Coletiva, 2005; 10(2), 323-331.

4. Ramos, DD, Lima, MADS. Acesso e acolhimento aos usuários em uma unidade de saúde de Porto Alegre, Rio Grande do Sul, Brasil. Cad. Saúde Pública, 2003; 19(1):2734, jan-fev.

5. Cotta et al. A satisfação dos usuários do Programa Saúde da Família: avaliando o cuidado em saúde. Revista Scientia Medica, 2005; 15(4), 227-234, out./dez.

6. Takeda S, Talbot, Y. Avaliar, uma responsabilidade. Rev Ciência Saúde Coletiva, 2006; 11(3); 569-571.

7. Pisco LA. A avaliação como instrumento de mudança Rev Ciência Saúde Coletiva, 2006; 11(3); 566-568.

8. Brasil. Ministério da Saúde. Departamento de Atenção Básica. Secretaria de Atenção à Saúde. Avaliação normativa do Programa Saúde da Família no Brasil: monitoramento da implantação e funcionamento das Equipes de Saúde da Família: 2001- 2002. Brasília, 2004. $140 \mathrm{p}$.

9. Tanaka YO, Melo C. Avaliação de Programas de Saúde do Adolescente: Um Modo de Fazer. São Paulo: Edusp, 2001.

10. Dean AG. et al. Epi Info, version 6: a word processing, database and statistic program for epidemiology on micro-computers. Atlanta: Centers for Disease Control, 1990
11. Queiroz MS. Estratégias de consumo em saúde entre famílias trabalhadoras. Caderno de Saúde Pública, Rio de Janeiro, 1993; 9(3); 272-282, jul./ set. 1993.

12. Teixeira SA. Avaliação dos usuários sobre o Programa de Saúde da Família em Vitória da Conquista - BA - Brasil. In: Fernandes A S, Juan ASP. (Org.). Experiências e desafios da atenção básica e saúde da família: caso Brasil. Brasília: Organização Pan-Americana da Saúde, 2004. 77-99.

13. Aguiar ACS, Moura ERF. Percepção do usuário sobre a atuação da equipe de saúde da família de um distrito de Caucaia - CE. Revista Brasileira em Promoção da Saúde, 2004 Fortaleza, 17(4) 163-169.

14. Brasil. Casa Civil. Subchefia para Assuntos Jurídicos. Constituição da República Federativa do Brasil de 1988. Disponível em: <http://www.planalto.gov.br/ ccivil_03/constituicao/constituicao.htm>. Acesso em: 20 out. 2013

15. Ronzani, TM, Silva CM. O Programa Saúde da Família segundo profissionais de saúde, gestores e usuários. Ciência e Saúde Coletiva, 2008 Rio de Janeiro, 13(1) 23-34.

16. Melo G, Santos RM, Trezza, MCSF. Entendimento e prática de ações educativas de profissionais do Programa Saúde da Família de São Sebastião-AL: detectando dificuldades. Revista Brasileira de Enfermagem, 2005 Brasília, 58(3), 290-295, maio/jun.

17. Cortez EA, Tocantins FR. Em busca de uma visão antropológica no Programa de Saúde da Família. Rev Bras Enferm 2006; 59(6): 800-804.

18. Jorge MSB, Guimarães JMX, Vieira LB, Paiva FDS, Silva DR, Pinto, AGA. Avaliação da qualidade do Programa Saúde da Família no Ceará: a satisfação dos usuários. Revista Baiana de Saúde Pública, Salvador, 2007 31(2), jul./dez.

19. Araújo, MFS et al. O Programa de Saúde da Família (PSF) sob a ótica dos usuários nas comunidades Santa Clara e Alto do Céu em João Pessoa-PB. CAOS Revista Eletrônica de Ciências Sociais, 9, 1-15, set. 2005. Disponível em: <http://www.cchla.ufpb.br/ caos>. Acesso em: 26 out. 2013.

20. Souza et al. Acesso e acolhimento na atenção básica: uma análise da percepção dos usuários e profissionais de saúde. Caderno de Saúde Pública, Rio de Janeiro, v. 24, 2008. Suplemento 1

21. Neves $\mathrm{CF}$ et al. Percepções da população sobre o programa saúde da família em Palmas-TO. Revista da UFG, v. 6, dez. 2004. Número especial.

22. Sberce L, Claus SM. O programa saúde da família na ótica de trabalhadores e usuários de saúde. Revista Boletim da Saúde, Porto Alegre, 2003 17(2); 123-132, jul./dez.

23. BRASIL. Ministério da Saúde. Secretaria de Políticas de Saúde. O trabalho do agente comunitário de saúde. 3. ed. Brasília, 2000. 119p.

24. Nascimento EPL, Correa CRS. O agente comunitário de saúde: formação, inserção e práticas. Caderno de Saúde Pública, Rio de Janeiro, 2008 24(6):1304-1313, Jun.

25. Mandú ENT, Gaíva MAM, Silva MA, Silva AM. Visita domiciliária sob o olhar de usuários do programa saúde da família. Revista Texto \& Contexto - Enfermagem, Florianópolis, 2008 17(1):131-140, jan./mar.

26. Brasil. Ministério da Saúde. Secretaria de Atenção Básica. Departamento de Atenção Básica. 
Coordenação Nacional de Saúde Bucal. Diretrizes da Política Nacional de Saúde Bucal, Brasília, 2004.

27. Carvalho, ML. Perfil e relação interprofissional da equipe de saúde do Programa de Saúde da Família (PSF) em cidades de pequeno porte. Araçatuba, 2008. 117 f. Tese (Doutorado em Odontologia Preventiva e Social) Faculdade de Odontologia da Universidade Estadual Paulista, Araçatuba, 2008.
28. Vaitsman J, Andrade GRB. Satisfação e responsividade: formas de medir a qualidade e a humanização da assistência à saúde. Ciência e Saúde Coletiva, Rio de Janeiro, 2005 10(3): 599-613.

29. Rodríguez WM, López CC. Satisfacción de usuários de consulta externa de especialidad em Instituto Nacional de Pediatria. Acta Pedriatrica del México, , 2002 (23):12-17. 